Andrzej Richling

\title{
THE CONCEPT OF THE NATURAL SYSTEM AND ITS IMPORTANCE FOR THE DEVELOPMENT OF INTEGRATED RESEARCH ON THE NATURAL ENVIRONMENT
}

\begin{abstract}
The development of the concept of an areal natural unit as a result of the needs of the economic practice and the popularisation of the general systems theory. Ecosystems and geosystems. Hierarchy of the natural system. Topological and chorological units. The issue of a universal natural unit. Applications. The influence of the concept under discussion on the development of the integrated research on the natural environement.
\end{abstract}

Keywords: holistic approach to nature, ecosystems and geosystems, partial natural systems, taxonomy of natural units.

The development of the concept of a complex natural unit treated as a system was clearly triggered and stimulated by the needs of the economic practice. It is understandable that units distinguished in connection with the differentiation of the entire natural environment or, at least, of its more important components constitute the best reference fields in the research on the state of the nature surrounding us and on the dynamics of its changes. Such units should be also used in evaluation and programming of the transformations of natural patterns. This assumption is not changed by the fact that most, if not all, spatial divisions are not of holistic character, despite of their authors' claims. It is worth noting here that the vast majority of research in the field of physical geography deals with the surfaces. The choice of the surfaces, the way in which they are delimited and their internal differentiation are of basic importance for the course of a research process and its success.

The general systems theory also contributes to the increasing popularity of the concept discussed here. An outline of this theory was presented for the first time by the Viennese biologist Ludvig von Bertanlanffy in Chicago in 1937 (Bertanlanffy, 1984). It was soon acknowledged as a theoretical and methodical basis of modern science treated comprehensively as opposed to its treatment as a collection of separate disciplines. The theory was developed first in biology, then in physics, and also in chemistry, mathematics and philosophy (Ashby, 1959). The application of this theory in research on the natural 
environment led to the treatment of the research object as an aggregation of systems. The distinguishing of such systems, their mapping and the determination of the structure, of the internal and external relationships, as well as of the dynamics of changes became the main subject of the landscape science. The application of the systems theory contributed also to the introduction of quantitative methods in natural science research and to the popularisation of the integrated approach and interdisciplinary research. In the last decades, the advent of computers and the development of remote sensing created favourable conditions for the development of the system approach in the research in question.

Natural units are defined in various ways. Regarding the definition formulated by $\mathrm{H}$. Barsch in 1979 one should note that units are treated as relatively closed entities, built from mutually connected geocomponents or of lowerorder systems. Interrelations among the components of natural systems are realised through exchange of matter, energy and information. Such units are most often called geosystems or ecosystems.

The term "geosystem" is used mostly by researchers dealing with the abiotic sphere, while the notion of "ecosystem" refers more often to the division of space of the living part of nature. It is worth noting, however, that the term "ecosystem", introduced to the literature by A.G. Tansley in the 1930s, was understood as a system including living organisms and their abiotic habitat. Fifty years later, A. Vink (1983) wrote that the notion of an ecosystem created a bridge between biology and physical geography. R. Forman and M. Godron (1986) are of the opinion that an ecosystem is a notion including structure, functioning and development. This notion can be applied to every spatial system. The notion of a geosystem is understood in a similar way. One could conclude that the two terms can be used interchangeably, although it is true that in the process of delimitation of ecosystems it is mostly (although not exclusively) components of the living nature that are taken into account, while in separation of geosystems it is characteristics of the relief, geological bedding and water conditions, but also land use and vegetation cover, that are used more often.

A. Kostrzewski consistently uses the term "geoecosystem" (Kostrzewski, 1993), emphasising this way the holistic approach to the issue of the typology of the natural landscape. It is hard to predict whether this term will replace names more commonly used nowadays. Perhaps tradition will prevail also in this case, but the popularisation of the term "geoecosystem" favours interdisciplinary research and, it seems, gains more and more proponents.

An important feature of a holistically understood natural system is the hierarchical character of its structure which means that the system is built from lower-order systems that, in turn, form entities with respect to units of the next taxonomic level. Z. Naveh and A. Lieberman (1984) write vividly that every natural system has two faces: that of the higher-order whole, looking downward and another one, that of the subordinated element, directed upwards. This point of view refers to the views of A. Koestler, who in his 
works (published in 1960-1982) proves that in the research on nature or on human society one should not reduce the subject of the research to a collection of elementary components. Instead, one should strive to select "smaller wholes" which he called "holons". Each holon is itself a whole and, at the same time, a part of a larger whole; the reality surrounding us consists of such wholes/parts.

The smallest natural units are commonly treated as homogeneous; this is supposed to mean that the way in which the individual elements of the natural environment are shaped on their entire surface doesn't change. This is of course a simplification, since changeability is a characteristic feature of every surface. The homogeneity of a spatial unit means that the changes are small and below a certain arbitrarily agreed upon level. Such units, called "topological" (from the Greek topos meaning "place"), are investigated from the point of view of the variability of the interrelations among the geocomponents ("vertical" relations). All "larger wholes", that is, spatial units called "chorological" (choros - "space"), are built from topological units. One should note that they too could be regarded as relatively homogenous. Research on chorological systems deals with the regularity of their patterns in space as well as with selection and mutual interaction of systems of lower taxonomical levels.

A postulate regarding the working out of a method of delimitation of the universal natural unit, which could be identified by means of various methods, has appeared several times in the works of natural scientists (Richling, Ostaszewska, 1993; Richling, 1999). The spatial dimension of such unit should be regarded in the same way by various specialists. The existence of such unit would create favourable conditions for the integration of natural sciences and for the comprehensive treatment of the natural environment issues. A universal natural unit could be a convenient field of reference in any discussions dealing with the functioning and transformations of the natural environment.

Attempts undertaken so far were however unsuccessful. It was impossible to agree on one view on the matter of the delimitation criteria. None of the procedures described in the literature is entirely holistic. The reason for that lies not only in the degree of the differentiation of the natural system but, above all, in the varied and subjective assumptions regarding the delimitation of the units. Spatial natural systems are delimited on the basis of selected characteristic features regarded as leading in the formation of the subordinated characteristics. There is also a hard-to-cross barrier between the structural approach (in which the pattern and the spatial distribution of the lower-order units decide about their selection and shape) and the functional approach (in which the natural spatial units are selected mostly in connection with the course of the selected processes).

In practice, spatial natural units are distinguished depending on the objective of the research, the character of the terrain and the accuracy of the considerations on the basis on various and not always comparable criteria. The analysis of their mutual relationships is conducted most often on the basis 


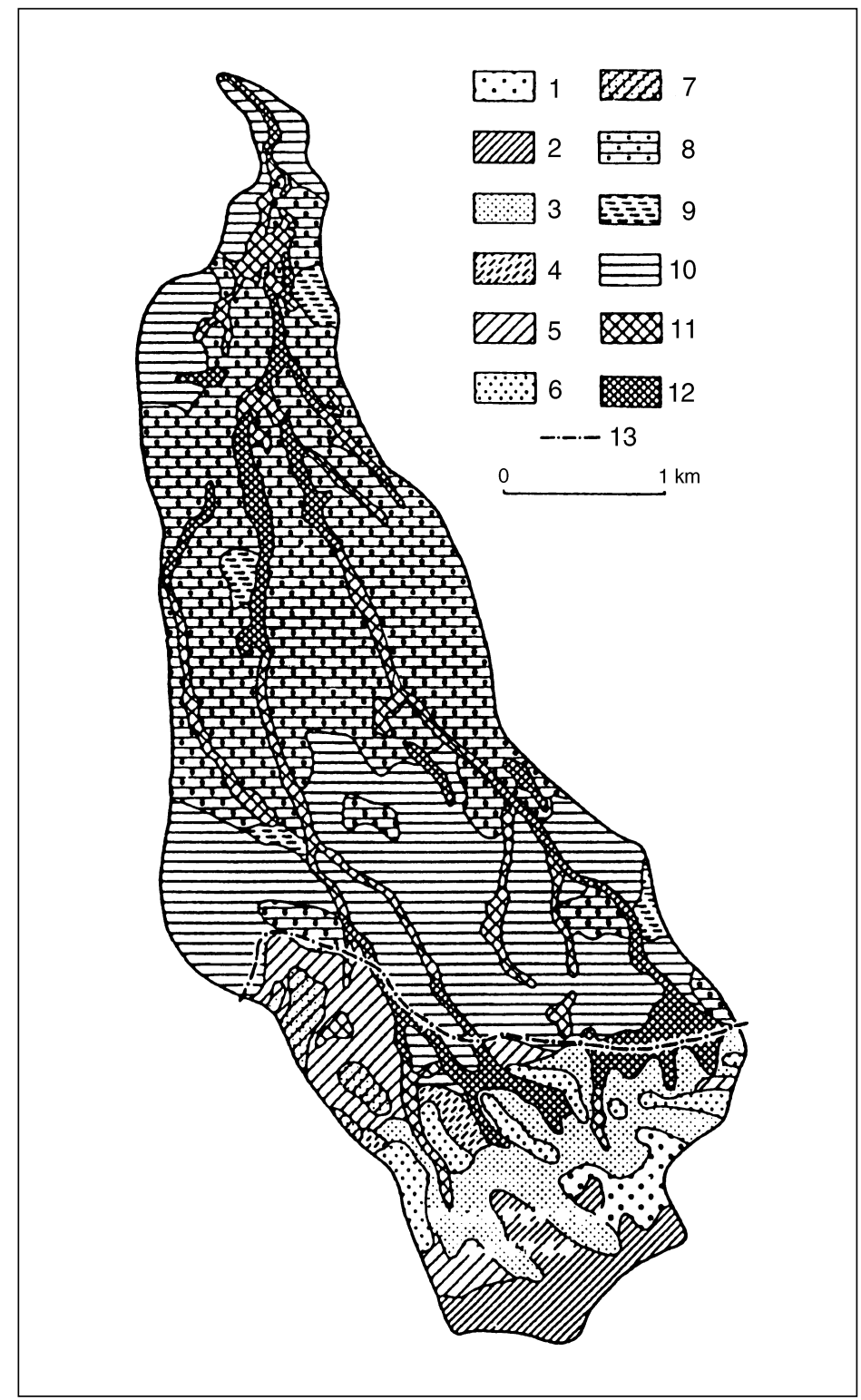

Fig. 1. An example of distinguishing partial geocomplexes. Types od hydrotopes in the catchment area of the Sucha River (west of Warsaw). 1- inflitration regime, of uplands; 2 - evapotranspiration-surface runoff regime, of uplands; 3 - infiltration-flow regime, of slopes; 4 - infiltration-flow-evapotranspiration regime, of slopes; 5 - flowish-evapotranspiration regime, of slopes; 6 - infiltration regime, of flatenning area within the slopes; 7 - evapotranspirationsurface runoff regime, of flatenning area within the slopes; 8 - infiltration-evapotranspiration regime, of plains; 9 - evapotranspiration-infiltration regime, of plains; 10 - evapotranspiration regime, of plains; 11 - floody-flow regime, of valleys; 12 - floody-flow-retention regime, of valleys; 13 - boundary of regions. 
of the concept of partial geocomplexes (Haase, 1964). Partial geocomplexes are distinguished in connection with the differentiation of the entire natural system, but with an emphasis on the role of given component (its feature) or specific process. The smallest partial units are called morphotopes, pedotopes, hydrotopes, climatopes and phytotopes. Each of these terms denotes a surface, quasi-homogenous from the given point of view. The described procedure is illustrated on the map of types of hydrotopes distinguished within the catchment area of the Sucha River (Fig. 1), as a result of a complex field mapping and the analysis of the relationships among the elements forming the natural system.

Investigation of relationships among the individual "topes" is possible only on the lowest taxonomical level. A fully homogenous unit is the point of reference here. Topological partial units may be identical with it with respect to the scope or else they may consist of a certain number of fully homogenous units (cf. Fig. 2). Spatial partial units of higher orders (chorological partial

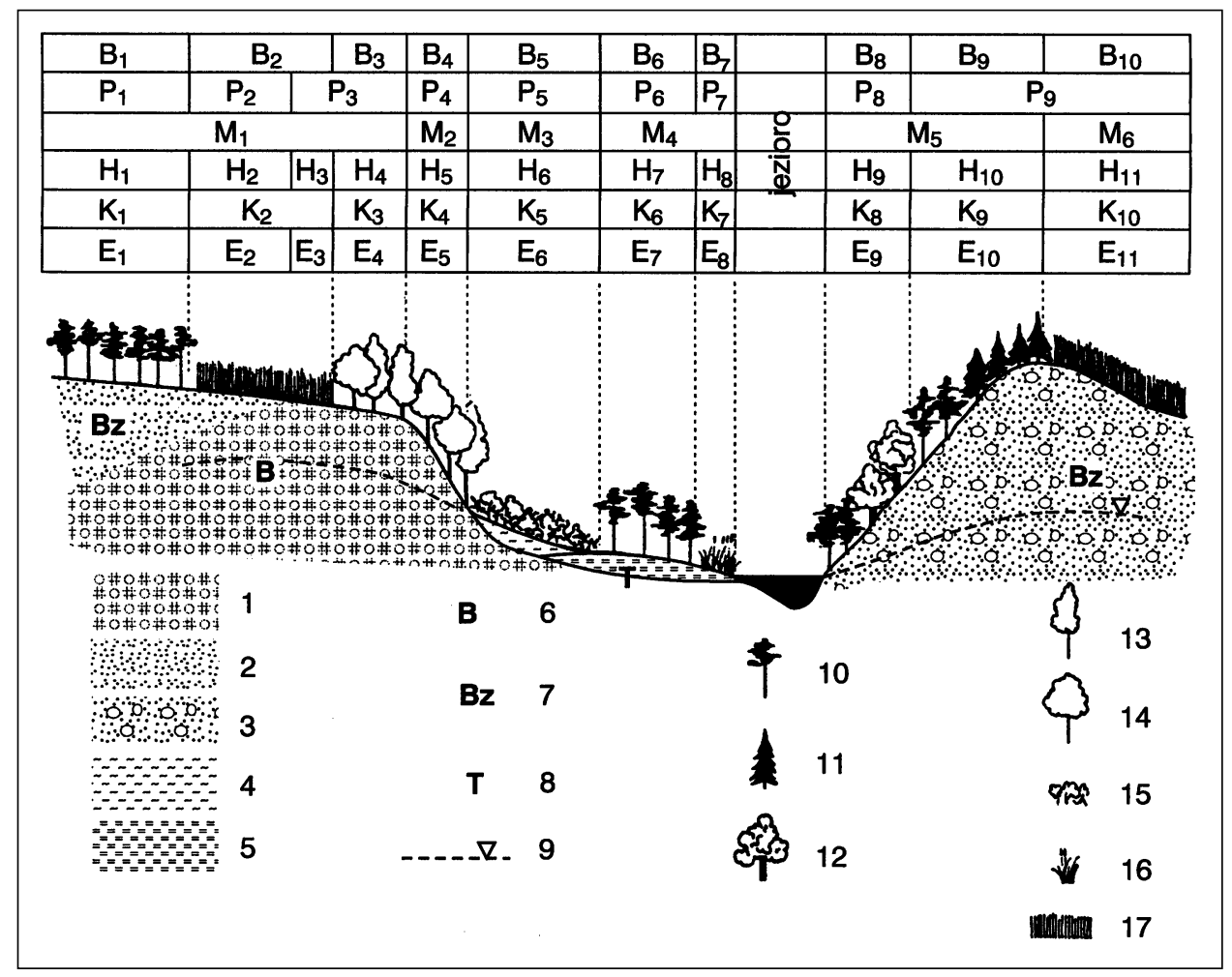

Fig. 2. Relations between full and partial topological geocomplexes (after G. Haase, 1967, modified). $\mathrm{E}$ - ecotopes, $\mathrm{K}$ - climatopes, $\mathrm{H}$ - hydrotopes, $\mathrm{M}$ - morphotopes, $\mathrm{P}$ - pedotopes, $\mathrm{B}-$ biotopes. Character of bedding: 1 - boulder clay, 2 - sands, 3 - stony sands, 4 - diluvial deposits, 5 - peat. Soils: 6 - brown soils, 7 - degraded brown soils, 8 - peat soils, 9 - groundwater table. Vegetation: 10 - pine tree, 11 - spruce, 12 - oak-tree, 13 - hornbeam, 14 - linden, 15 - willow brush, 16 - rushes, 17 - corn crops. 
units are formed by joining together topological units. The process of joining is governed by various principles; therefore, various and not comparable associations occur. Both catchment areas and climate or geobotanic regions may result from the joining of topological partial geosystems. As follows from the above, only units of topological dimension may approximately function as universal natural units. Analysis conducted in the topological scale, however, deals with small surfaces; it is not possible to obtain characterization of the natural environment of large fragments of the Earth's surface this way.

To conclude, one should emphasise once again the role of the natural spatial divisions for the work of applied character. As it was mentioned at the beginning, synthetic research on the natural environment developed in a close connection with practical needs. Estimation of the terrain's predisposition for any given purpose, analysis of the method of utilisation of the specific natural resources or prediction of the changes of natural conditions affected by a given investment require a holistic approach, in which the entire natural systems, and not just their individual features, are investigated. Holistic system research is also stimulated by the increasing threat caused by the disadvantageous changes of nature both on the local and on the regional scales, as well as on the global scale.

The current situation of the holistic trend in geography has been visibly affected by the development of landscape ecology. The notion was introduced in 1930 by Troll to denote a discipline investigating the functional content of landscape and explaining its multi-directional and changing interrelationships (Troll, 1950). Landscape ecology is nowadays referred to as an interdisciplinary field of research or a separate discipline dealing primarily with the relations between nature and human activity. It brings together specialists with varying backgrounds. The attractiveness of this approach lies in the possibility of co-operation of different specialists and the opportunity to confront the methods applied by various disciplines, mainly geography and biology. It turns out more and more frequently that the majority of solutions applied in physical geography studies can be used in the research of the living part of nature, especially with regard to spatial aspects of biotic systems, and that the methods used in ecology can enhance our knowledge of the mode of functioning of abiotic systems.

In Poland, first studies in this direction were led immediately after World War II within the field of study called "urban physiography", to assist the planning of the rebuilding and development of the destroyed cities. In the 1960 s, J. Kondracki initiated an intensive development of the holistically oriented research; first comprehensive studies of the natural environment, closed by the delimitation of spatial units treated as systems were conducted on his initiative. He has also worked out a typology of the natural landscape of Poland and a physico-geographical regionalisation. Since then, landscapegeographical studies have developed in many geographical centres in Poland.

The popularisation of the system approach in natural sciences contributed in a visible way to the strengthening of trend to conduct team and inter- 
disciplinary research. The interest in co-operation among the specialists representing various scientific disciplines is increasing. Research methods used in the past only within the individual scientific disciplines are used more and more widely. More publications are works by several authors, often with varying backgrounds. The number of research projects conducted by international teams is also increasing.

More and more frequently, spatial natural units are used as fields of estimation in spatial planning and other endeavours dealing with evaluation and management of natural resources. It should be mentioned that Kondracki's regionalisation of Poland appeared in the official publication "Geographical names of the Republic of Poland" (1991), and that the names of the regions are commonly used and can be encountered in publications, also in cartographic publications addressed to non-specialists.

\section{REFERENCES}

Ashby W.R., 1958, General Systems Theory as a New Discipline, General Systems vol. III, New York.

Barsch H., 1979, W sprawie pojęć dotyczących powłoki ziemskiej i jej przestrzennego rozczłonkowania w terminologii nauki o krajobrazie [Zur Kennzeichnung der Erdhülle und ihrer räumlichen Gliederung in der landschaftskundlichen Terminologie; Polish translation], Przegl. Zagran. Lit. Geogr., vol. 2.

B ertanla nffy L. von, 1984, Ogólna teoria systemów-podstawy, rozwój, zastosowania [General Systems Theory: Fundamentals, Development, Applications; Polish translation], PWN, Warszawa.

Forman R.T.T., Godron M., 1986, Landscape Ecology, J. Wiley and Sons, New York.

H a s e G., 1964, Landschaftsökologische Detailuntersuchung und naturräumliche Gliederung, Pet. Geogr. Mitt. 1-2.

Kostrzewski A., 1993, Geoekosystem obszarów nizinnych - koncepcja metodologiczna [Sum.: The Geoecosystem of Lowland Areas. A Methodological Conception; in Polish], Komitet Naukowy przy Prezydium PAN “Człowiek i Środowisko”, Zeszyty Naukowe, 6.

Naveh Z., Lieberman A., 1984, Landscape Ecology - Theory and Application, Springer Verlag, New York.

Richling A., 1999, On the Universal Natural Areal Unit, in: Landscape Synthesis. Concepts and Applications, M.R. Moss, R.J. Milne (eds.), Faculty of Environmental Sciences, University of Guelph, Canada; Faculty of Geography and Regional Studies, University of Warsaw, Poland.

Richling A., Ostaszewska K., 1993, Czy istnieje uniwersalna jednostka przyrodnicza? [Sum.: Does a Universal Natural Areal Unit Exist; in Polish], Przegl. Geogr., 64 (1-2).

Troll C., 1950, Die geographische Landschaft und ihre Erforschung - Studium Generale 3, Arbeiten aus dem Geogr. Inst. der Universität Bonn, 1, 5.

Vink A.P.A., 1983, Landscape Ecology and Land Use, Longman, London-New York. 